\title{
Community Based Participatory Research as a Long-Term Process: Reflections on Becoming Partners in Understanding Social Dimensions of Mining in the Yukon
}

\author{
Gertrude Saxinger \\ University of Vienna \\ First Nation of Na-Cho Nyäk Dun \\ Mayo, Yukon
}

\begin{abstract}
North American Indigenous communities increasingly demand a community-based participatory research (CBPR) approach to social and natural sciences research undertaken on their traditional territories. This article outlines key principles of CBPR, reflecting on the "social licence to research" and how research in anthropology and other social sciences has been practised in the past. The article illustrates elements of establishing partnerships, knowledge sharing, knowledge co-production, and data and research-product ownership. It also stresses the need for long-term relationships in a research partnership in order to build trust between the involved parties and to provide meaningful outcomes. It highlights benefits and also the challenges that come along with CBPR practice and argues that time is the essential asset in a successful CBPR project. The article is based on experiences in the research project LACE-Labour Mobility and Community Participation in the Extractive Industries, Yukonhosted from 2014 to 2018 by the community of the First Nation of Na-Cho Nyäk Dun, the "Big River People," in Mayo, Yukon, Canada.
\end{abstract}

The Northern Review 47 (2018): 187-207

Published by Yukon College, Whitehorse, Canada 


\section{Introduction}

North American Indigenous communities increasingly demand a community-based participatory research (CBPR) approach to social and natural sciences research undertaken on their traditional territories. This demand results from Indigenous experiences in the colonial and postcolonial past when "helicopter research" was unfortunately commonresearchers would come into a community for a short period of time and did not provide feedback about the knowledge they gained from local interlocutors. This problem has not only been North American, it has prevailed around the globe.

Access to data and ownership of data-particularly with respect to traditional ecological knowledge and Indigenous knowledge, but also any local knowledge in general-rests in many cases not with the local knowledge holders, but with researchers. These problems, along with scientists' misconceptions of knowledge sharing, were addressed in 2007 and again in 2014 by the Canadian-based First Nations Information Governance Committee and the First Nations Regional Health Survey, based on first documents developed in 1998 (First Nations Centre 2014, 2).

Together, they developed what is today called the OCAP policyOwnership, Control, Access and Possession. This is a guideline tool for local communities to facilitate research on their land. At the same time, it is a guideline for incoming researchers (First Nations Centre 2014). This policy is straightforward and demands doing away with "[s]ocial research [that] was used as 'an instrument of oppression, imperialism and colonialism'"' (First Nations Centre 2007, 3). Furthermore, OCAP outlines that "[n]egative experiences have led First Nations to feel distrustful and reluctant to participate in social research. Past research practices were often disrespectful, damaging and stigmatizing to First Nation people" (First Nations Centre 2007, 3). OCAP also insists that First Nations assert their authority over all research concerning their communities: "[t]his includes the right to make decisions about what, why, how and by whom information is collected, as well as how it will be used and shared" (First Nations Centre 2007, 4).

Applying OCAP therefore means establishing a research relationship of equity, joint interests, and benefits, as well as access to and possession of knowledge by the knowledge holders. Along these lines Holkup et al. (2004) - who define CBPR as "action research" - formulate characteristics of CBPR based on the example of health research. Among other features, 
CBPR builds on the strengths and resources of the community, promoting co-learning among research partners, achieving a balance between research and action that mutually benefits both the community and science. They emphasize the relevance of community-defined problems as well as disseminating knowledge gained from the CBPR project to and by all involved partners, a process requiring long-term commitment on the part of all partners (Holkup et al. 2004, 3-4).

These principles lay out that research should take place within sustainable partnerships, which includes decision-making about the ownership of the research products (Norris et al. 2007). "Action research" also means that applied and basic research should be combined (Jones \& Wells 2007). This approach is thus transdisciplinary when communities gain knowledge about their own society and are supported in policies for societal change (Minkler 2010; Gong et al. 2009).

This article lays out some reflections and insights on elements of knowledge sharing, knowledge co-production, and data and researchproduct ownership. It also stresses the need for long-term relations in a research partnership in order to build trust between the involved parties and enable meaningful outcomes.

The article draws on the experiences gained in the research project "LACE - Labour Mobility and Community Participation in the Extractive Industries, Yukon." This project was part of a larger research initiative, "Resources and Sustainable Development in the Arctic" (ReSDA). The article provides reflections of the author, who is the principal investigator of LACE. It includes aspects of the collaboration with a PhD student, Susanna Gartler, and addresses the framework of cooperation with the First Nation of Na-Cho Nyäk Dun in Mayo, Yukon. Therefore, this article is my personal reflection of the CBPR elements in LACE and it was reviewed and approved by the research partners, the First Nation of NaCho Nyäk Dun, who are co-authors. The thoughts presented below rest on self-observation over three years of the project, and are based on the author's research notes containing reflections on the research process with friends and community members in Mayo.

The article is organized in the following way. First, some contemporary and historical considerations about the "social licence to research" are outlined. This is followed by a section on how the research partnership between the First Nation of Na-Cho Nyäk Dun and the LACE project developed, including some reflections on how LACE was introduced to the community and how joint research aims were defined. This is followsed by a description of the jointly owned and produced products resulting 
from the project. Finally, concluding remarks highlight how essential is time, when partnerships and a joint project evolve with CBPR methods.

\section{The Social Licence to Research}

Community-based participatory research rests on the principle of joint production of applied and academic knowledge. This principle highlights that both parties, the community where research takes place and the incoming researcher(s), should benefit from the research endeavour in equal ways and build on a relationship characterized by equity (Holkup et al. 2004, 3-4).

Such an approach has not always been applied in the past, neither in social sciences nor in the natural sciences. Therefore, these research approaches did not have a "social licence to research" from community members. Too often it was the case that visiting researchers treated the local populations - in what the researchers considered "exotic places" as research objects, and too often they did not ask for proper permission to conduct research. This type of "othering" of Indigenous peoples and strangers in general (Barth et al. 2005) has been heavily discussed and criticized in social and cultural anthropology from the 1980s onwards. I am referring here in particular to the critique of "culture," a concept that may separate the human society into distinct categories and groups of strangers (Abu-Lughod 1991). If such concepts are employed in uncritical ways, equality between parties in research projects cannot be achieved. Researchers too often took advantage of being representatives of colonial powers and introduced their research objectives in a uncooperative way to the local population.

Another aspect is the way in which researchers inform project participants about outcomes and results. When research is perceived to have its own rights and is being done for the scientific community alone, a great misunderstanding is provoked. Local communities become sole objects and knowledge providers instead of sovereign knowledge holders. Too often results are not fed back thoroughly or effectively to the communities who participated. Knowledge went elsewhere and could not be used by local communities to learn from or to utilize for understanding their own social processes. Western science thus failed to foster change (Holkup et al. 2007). Science largely resisted change within itself. Knowledge production and transfer tools fit the model of a Western knowledge system that may have been inaccessible to the community participants. Furthermore, in many cases, projects failed to provide local 
people with access to data and the insights that were collected from knowledge holders (First Nations Centre 2014).

Although more recent years have shown success stories of CBPR projects and an increasing understanding of the approach, and communities' needs are prevailing, the problematic approach to research is in anthropology historically marked by the introduction of the anthropologists' main research method, "participant observation," by anthropologist Bronislaw Malinowski in the mid 1910s. Although researchers and travel writers of many centuries earlier sported a similar attitude, it was Malinowski's claim for a more scientific understanding of local communities (in his case the Trobriand Islanders north of Australia) based on long-term observation of everyday practices going on among local people and learning the local language (Malinowski 2014 [1922]): one aspect in Malinowski's research method was to be as close as possible to the people. Although he had good intentions for the advancement of scientific anthropology, the researchers' long stay in the community created special conditions for the locals and one has to ask from today's perspective how comfortable the locals were with the visitors who interfered in their daily life and probably treated them as objects of observation. Under colonial rule people scarcely had the chance to say no. Anthropologists did not always have success in finding their way into a community, exactly because of lacking the community's consent. This is illustrated by Edward Evans-Pritchard who did anthropological research in Africa in the mid- twentieth century after the Nuer people stood up against the British colonial regime. He was perceived as a representative of the colonial power (Barth et al. 2005). He still found his way into the community, but it is unclear under what research conditions. It is also unclear how much influence this problematic relationship with the people actually had on the soundness of his research results.

An entirely different approach was pursued by the end of the nineteenth century and early twentieth century by the German born American anthropologist Franz Boas, who closely collaborated in his British Columbia West Coast research with informant-and anthropologist in his own right-George Hunt. Hunt grew up in Tsaxis (Fort Rupert) and was the son of a Tlingit (Taant'akwáan/Tongass) woman and a Hudson's Bay Company fur trader from England. He spoke his mother's tongue, English, and Kwak'wala, the language of the Kwakwaka'wakw (Kwakiutl) fluently. He was closely engaged in Boas' fieldwork and thus it became their joint work. They co-authored publications, and Boas also acknowledged Hunt; this attitude was rare at the time. In the year 1893 Hunt and Boas 
organized an exhibition at the World's Columbian Exposition in Chicago (the Chicago World Fair) (Barth et al. 2005). This early cooperative research approach was also in line with Boas' own guiding principle, which was to fight against the cultural loss of the world's Indigenous peoples. For him anthropology was a way to protect cultural heritage and he was active, together with Hunt, to record and study local languages. He was aware by the turn of the last century that Indigenous cultures will change soon and rapidly. In this way he already included elements of "action research," which is part of CBPR today (Holkup et al. 2004; First Nations Centre 2007; Gong et al. 2009; Gehlert et al. 2012). However, Boas alone became the famous anthropologist and his work has been recited as "his research" in the history of anthropology, which again dispossesses people from dignity and authority in a colonial manner.

Soundness of research is key to producing accurate knowledge (Holkup et al. 2004). This accuracy can particularly be achieved with CBPR when both the knowledge holders and the researchers together reflect on the insights and interpretations of the subject matter. In cases where the project is welcome and is perceived as being relevant for the community, people will more likely be open and can provide knowledge, experiences, viewpoints, and opinions to the researcher. In some casesas we have also experienced in our research when we tried to include another community for comparative purposes-communities refuse for many good reasons and when it is not useful for them to become part of a research project.

Joint publications and joint knowledge products can be outcomes that portray, in a sound way, perceptions and interpretations of local knowledge holders, local research associates, and outside researchers. These products also involve consensus among the stakeholders in research regarding the outcomes, and show a common understanding. Needless to say, this work also involves a lot of effort on the part of the involved Indigenous community who in many cases lack the time to deal with outside researchers. Therefore, I argue for long-term relationships that allow the community the space to reflect on findings at their own pace-sometimes this involves a long publication time, which rightfully challenges the power of the neo-liberal high-speed scientific publication industry.

The social licence to research reflects not only a core moral value in human interactions in general, it is also the prerequisite to produce sound knowledge for practical applications and scientific advancements. The social licence rests on the stakeholders' relationships to each other, which 
are gauged by the degree of trust. Trust, however, does not necessarily evolve quickly or without drawbacks. The next section will outline some reflections from the LACE project regarding this issue.

\section{Setting Up the Partnership}

In 2014 Susanna Gartler and I came to the Yukon with a research idea and some funding in our hands. We addressed the First Nation of NaCho Nyäk Dun in Mayo, Yukon, as this community has a long tradition of mining on its traditional territory with the Keno Hill mines operating from the 1910s onwards. When we arrived, one mine was operating and at the time of writing new extractive projects are under way. Together with Joella Hogan, the First Nation's heritage manager, we started to set up a research partnership with the First Nation of Na-Cho Nyäk Dun. Hogan is herself university trained and we could easily develop a joint language. She very well understands anthropologists' methods and could at the same time introduce us to the specifics and characteristics of the community as well as the critical points of doing research in Mayo. She knows what the concerns of the community are when it comes to mining. Furthermore, she knows very well which kind of research has priority for her First Nation. In the initial talks it became clear that mining was not at all the first priority. Much more pressing issues considered for research included cultural heritage and cultural revitalization, Northern Tutchone language and place names, social issues, land use planning, and much more.

However, gradually we found out that the mining issue has a lot of history in common with the colonial history in the Mayo region. Moreover, it became clear that the concrete topics of our research-labour mobility and working in the mines, workers living in camps and being away from home for rotational shift work, and the employment opportunities of local people in the mining sector-had a lot to do with social and employment issues relevant to Mayo. It took us some time to lay out the project in a way that it could meet the interests and demands of the community. Instead of a straightforward process, the project required thinking from both "ends," the community representatives as well as the researchers. Chief and Council approved our project after identifying benefits, and we were introduced to the research protocols and codes of conduct when pursuing a project in the community.

Joella Hogan, the heritage manager, took on the role of being our point of communication with Chief and Council in the everyday matters, and she introduced us to key informants in the community. Hogan took 
on the responsibility to oversee our activities and ensure that all was in line with the research protocol. This is for sure not an easy task since the heritage manager was already burdened with other work resulting from her main job priorities. Overseeing our research was an additional task, and we particularly acknowledge her willingness to support the project. In fact, research projects fail when local authorities simply do not have the time to deal with incoming researchers.

By the end of the LACE project in year three, the self-government of the First Nation of Na-Cho Nyäk Dun invited us to continue with research beyond the scope of the original project. Needless to say, this is the best possible outcome of a final presentation to the research partners. Future themes could be, for example, long-term monitoring of social impacts from a new gold mining project or other topics of relevance to the community to be identified in the future.

\section{Introducing LACE to the Community}

It was of utmost importance that we quickly produced non-academic leaflets and plain language project descriptions that outlined what we were going to do in the community. In this way we could approach individuals for their participation as interview partners and interlocutors to share their knowledge at an early stage. Communication can fail if project descriptions, cover letters of consent forms, and other material is in technical or abstract academic language. It is tiring for people not involved in academia to read such material.

The first field trip together with Susanna Gartler in spring 2014 was primarily a mission to establish a partnership and to do some preliminary interviews. A second field trip followed by myself in October of the same year; a couple of field trips followed in the next years together with Susanna Gartler and also by the two of us individually. By the end of year one the official cooperation was already settled and now it was time to inform the community in general about what would be studied in their village over the next few years.

Getting a research project started in a community takes time and often funding for this initial development stage is not available. Funders expect to have the partnership in place from the outset, but forget that starting a partnership can take many months. In our case, we had the funds already in place. In a way, this also bears some risk since no one can predict that a community will accept a project for further development. But it is essential 
that time for setting up a project and, if need be, finding an appropriate community for it to take place, is part of the overall budgeting.

During the second field trip in year one, I connected with individual people, and the project and the team were introduced step by step to community members. In year two, Joella Hogan and I together held a larger project presentation in the community hall and I introduced some preliminary findings. This information fleshed out the project with some concrete details and was not just an abstract presentation of research plans. I was informed that food "opens up the hearts" and in this light I cooked dinner for this presentation. It was a great experience for me to be able to work with Mayo resident Beverly "Buffy" Genier in the kitchen for the whole day. While cooking with Genier, who also has long-term experience working for mines, I was able to learn a lot. The Austrian beef dish "Gulash" was soon transferred into "Moolash" when she shared a pile of moose meat with me. Around fifty people attended, which is the equivalent of approximately twelve percent of the population. I was surprised and glad about this outcome. By then, I could already share with the community the little booklet "Behind the Scenes in Mining in Mayo," based on my insights in year one (Saxinger and Gartler 2015).

At this time it was not yet clear where this research would lead us. It was in an infant stage and we did not know each other very well. By this time I felt we did not yet have a fully-fledged partnership but I was glad that I was accepted well as a person and as a researcher with the project in the community. Developing trust and partnership has been a process over the years and it is still going on. The quality of a relationship changes positively through the passage of time: friendships are established, and people get interested in what we are doing and what the research can mean for them. At the same time, throughout the project people were asking what exactly we were doing there. One can never reach out to each and every one and a community presentation is not enough to engage with all. Not every citizen may agree with allowing a research project and researchers in the community. Since anthropological fieldwork involves longer stays in a community, it provides time to sincerely engage with individuals. In focus group discussions, in individual interviews, and in many informal talks, we could explain our research aim and why we were in this particular community and not in another. It takes time to sit down with people to yarn over everyday life, to get to know each other, to share stories, and to build trust. 


\section{Jointly Developing Research Aims}

Our partnership developed over years. Providing research material that is perceived as beneficial helped deepen the relationship. Some outcomes became visible over time and some not until the far end of the project. Our materials ranged from a jointly published booklet called the "Mobile Workers Guide-Fly-in/Fly-out and Rotational Shift Work in Mining. Yukon Experiences" for the mining workforce as well as two colourful brochures with preliminary insights and stories of the local interlocutors. One brochure is on contemporary employment in mining, published in the beginning of year two (Saxinger \& Gartler 2015), and one is on the colonial history of mining in the region and the memories of Elders, which was published in year three (Saxinger \& Gartler 2016).

In year two, Susanna Gartler gradually started to develop a spin-off project. Her initial role in LACE was to study the memories of Elders about mining over the last century in Mayo, including the colonial past shaped primarily by the extractive industry. This topic led her to come across the consequences of colonialism, which results today in cultural revitalization activities in the community. She is now studying for her doctoral dissertation, in collaboration with the First Nation of Na-Cho Nyäk Dun's Heritage Department, the construction of the new cultural centre in Mayo (Gartler, Hogan, Saxinger submitted 2017). This collaborative endeavour is still ongoing and goes beyond LACE.

A key idea was also to produce the video film "Mining on First Nation Land" (Saxinger et al. 2017) in year three, together with knowledge holders and the First Nation of Na-Cho Nyäk Dun self-government representatives. The film demonstrates their attitude to mining and how they think mining should take place on their traditional territory. Bringing the opportunity to the community to release their demands to the public-in this case the communication of their attitude to mining - has been one of my personal highlights in CBPR. Gradually we felt accepted in the community and among its representatives.

Too often research results in scientific papers alone. Needless to say, the main results are often only visible at the end of a project. The "Mobile Workers Guide" and the video "Mining on First Nation Land" were released only in the last year. After approval by Chief and Council the film was screened at a larger community presentation that included the release of the "Mobile Workers Guide" and showed the key results of the last three years of research in Mayo. For some communities these long time frames in anthropological work are uncommon. Others have more experience with this type of research and may not expect swift results. 


\section{Identifying Mutual Benefits - Jointly Owned Products}

A key to true CBPR is the shared benefit resulting from research projects (Holkup 2004). As outlined above, a common question in the context of research is "what are the benefits for us as a First Nation" as it was for the LACE project as well. While introducing some of the participatory elements, such as working with Liz Blair, a local research collaborator, and the idea to involve youth, it was also highlighted that the "Mobile Workers Guide" supports the local workforce in coping with the challenges brought about by being away from home and living in camps. This is currently of utmost importance since a new gold mine will start operations near Mayo in 2018. Plans are to hire about 200 people in the construction phase, on a rotational shift-work basis. As outlined in the Community Benefit Agreements (CBAs) negotiated by the First Nation of Na-Cho Nyäk Dun and the operating companies, local hires are required; see further below.

The principles of CBPR include supporting societal change with research (Holkup 2004). This means that research and its results should support local communities and local governments in their desire to steer ongoing social changes or to lay out policies for future changes in their community. In this context I must state that for a researcher, a modest approach is essential. Too often outsiders come to town with ideas that they find appropriate for facilitating changes, but which are often defined by outsiders. This approach was heavily criticized decades ago in development projects and in the "development business" in particular across the Global South. Here, development meant a pathway to the lifestyle of the industrialized Western world. Hence this lesson is a key to self-reflection for visiting researchers who often see themselves in the position "to help" without even asking if (their) help is needed (Rahnema \& Bawtree 1997).

Nevertheless, social change is happening everywhere at any time and local governments create policies for facilitating these changes. To the community of Mayo, and for the First Nation of Na-Cho Nyäk Dun, rapid social change came over a century ago with the introduction of the mining industry. In addition to this, a major societal change was brought about by the residential school system for Indigenous people in Canada. Dating back to the early twentieth century, children were separated from the land and their parents to be "educated" or, rather, assimilated in public or missionary schools far away from home. The prohibition to speak their Indigenous language, violence, and general neglect of their psychological and emotional needs (Krömer 2016), led to what the Final Report of the 
Truth and Reconciliation Commission termed "cultural genocide" (Truth and Reconciliation Commission of Canada 2015). The consequences are still visible today and this loss of culture, and the current cultural revitalization, are just two of the issues that are tackled by the various First Nations self-governments in the Yukon.

Development policies envisioning a healthy future for citizens are implemented by the First Nation of Na-Cho Nyäk Dun self-government. One part of this is illustrated by the existing Comprehensive Benefit Agreements (CBAs) that are negotiated by the First Nation of $\mathrm{Na}-\mathrm{Cho}$ Nyäk Dun self-government with the mining companies that have projects on their traditional territory. In these CBAs, training for local citizens and employment opportunities are set out. Companies must commit to engage with the local hosts in a meaningful way, must support local socioeconomic development, and must mitigate negative impacts from mining.

We hope that some of our research results will support the First Nation of Na-Cho Nyäk Dun in knowledge collection, and support societal changes that break the colonial legacy. The key materials are outlined in further detail in the following sections.

\section{The Mobile Workers Guide}

The Mobile Workers Guide-Fly-in/Fly-out and Rotational Shift Work in Mining. Yukon Experiences (Saxinger \& Gartler 2017) is one of the research products - available online open access and in print-from the Labour Mobility and Community Participation in the Extractive Industries (LACE) project, which tries to foster positive change. Recognizing that addressing social change is one of the principles in CBPR, change in this case has meant offering both existing workers, and those who are interested to work in this sector, some tools to cope better with the challenges that accompany this lifestyle. The Mobile Workers Guide presents a wide range of insights into a work life that is characterized by mobility, living in camps, and being away from home for scheduled periods. In the guide, experienced workers (both men and women) from a variety of professions in the exploration and mining sector provide insight for those who are new to the industry. They share stories, experiences, and strategies for coping with potential difficulties, and tips for how to benefit from this travelling lifestyle. The sections of the guide introduce readers to

topics such as coping with boom-and-bust cycles, the specifics of mining communities, how to enter the sector as First Nation people, women in mining, family life and private relationships, income management, and career development. 
Having the First Nation of Na-Cho Nyäk Dun as co-publisher of the Mobile Workers Guide demonstrates a highly active approach by the community towards the mining sector. The guide serves as a tool to show the challenges that need to be mitigated by the company, their management, and their human resources departments. Mitigating negative impacts from rotational shift-work should not rest on the workers' shoulders alone. At the same time, the Mobile Workers Guide also demonstrates benefits that come to the community with mining projects. In this way the guide is a support tool and at the same time probably also a political statement; it is a call for good working conditions and for the anti-racist inclusion of Indigenous employees in the mining sector.

\section{Youth "Multi Media"}

Another community based research activity was planned with the title "Youth Multi Media" (YMM). This is an example where we were not successful. Film is an essential tool to engage community members, to train youth and others, to hear stories and opinions (Kassi et al. 2017). This approach can serve the engaged people, the engaged community, and the researchers to gain data and knowledge about what goes on in a community. YMM was designed to train youth in video storytelling with very basic and easily employable tools (Graybill 2015). The idea was that youth use video to collect opinions in the community about mining and to portray their own attitudes to the sector.

Two constraints led to this part of the project ultimately not being realized. First, the university's ethics review board did not give permission to work with youth under sixteen years of age. We then had time constraints for resubmitting the documents to the ethics review board with more detailed explanations about why youth under sixteen should be included. Nevertheless, the age group around fourteen were those most interested in taking part. We partnered with the First Nation of NaCho Nyäk Dun self-government's youth coordinator, Josephine Hager, to address young people. The timing was during spring break when most of the students were on vacation from school and had spare time. The second constraint was that the older youth-over age sixteen-already had jobs, were travelling at the time, or were less interested. As Kassi et al. (2017) show, filmmaking brings qualifications to the community, lets the youth speak, and addresses new media that is relevant in the everyday life of youth. A new (interregional and cross-Arctic) project is in the planning phase and we will identify new ways to address youth under sixteen, design the timing in a better way (summer instead of spring break), and 
lay out the design in a way that the university's ethics review board will approve participation of early teens.

\section{Youth Lunches and School Presentation}

LACE did reach out and engage youth in other ways. While primarily adults attended the community presentations (one in the first year and one in the last year), the knowledge transfer and communication to the younger generation was still one key element of this research. Together with the First Nation of Na-Cho Nyäk Dun youth worker, Josephine Hager, I organized two youth lunches. During the school's lunch break we could sit together in a good atmosphere and talk about mining on the First Nation of Na-Cho Nyäk Dun traditional territory. It was also a space to learn from youth about the key issues that interest them.

High-school students at J.V. Clark School in Mayo were engaged in presentations about stories from miners and others working in a variety of jobs in this sector. I presented a slide show of work places, camps, and other facilities. None of the students had yet seen the actual mining sites. Some of the youth had quite a good idea since their parents were involved in this sector. I was impressed how strongly engaged they were in the discussions when I asked details regarding their concerns about mining as well as their own expectations to get a mining-related job, or why some are not at all interested in this job market. I learned how much knowledge young people have about what is taking place on their land; at the same time, I talked about what I had learned so far and about my impressions from my visits to the mining sites and camps. I really felt that the LACE project could support raising awareness among youth to get informed about what is taking place on their land.

\section{Video: Mining on First Nation Land}

"Mining on First Nation Land. The First Nation of Na-Cho Nyäk Dun" (Saxinger et al. 2017) is a thirteen-minute film telling stories and expressing opinions of people from Mayo related to mining on their traditional territory. Its goal is to inform the interested public, incoming mining and exploration companies, researchers, and other interested institutions about the community's and its representatives' diversity of attitudes and opinions about the mining industry. The film shows the long-term history of mining dating back one hundred years, including the colonial history. It highlights societal challenges and topics such as employment and training in mining as well as environmental concerns. It is also of 
particular interest to local people and members of the First Nation of NaCho Nyäk Dun who may not be familiar with what exactly mining means to the community.

The film was produced by the First Nation of Na-Cho Nyäk Dun and made by the LACE research team. Having the First Nation as producer of this activity has been essential for the film's success. Only with the support and the commitment of the community was it possible to reach out to interview partners and participants in the video. The film is carried by its protagonists who speak without an outside narrator. I am convinced that the film was possible only in the third year when the research and film team were settled and known in the community. The participants already knew what the LACE project's aims were, and we in turn worked with interlocutors who we mostly knew well. In this way, we knew who would contribute to which topic in particular. The narrations of the participants were therefore more natural. Again, it takes some time to obtain the trust of people so that they can be confident that the final product will reflect their opinions accurately.

Such film productions need time, however, and a lot of flexibility by the team since the project cannot always go along a pre-set script. Serendipity is key here. The interviews have been so rich that a second film could develop from the same material-for example, looking at colonial experiences and the subsequent cultural revitalization processes. Before the official release on the YouTube channel, the film was given consent by the Chief and Council of the First Nation of Na-Cho Nyäk Dun as well as by all participants who are shown in it. Chief and Council also suggested producing a sequel in the context of a potential new project on mining impacts.

Both the Mobile Workers Guide and the video Mining on First Nation Land were presented in eight Yukon communities during a tour in the project's final year by our team in collaboration with the local community campuses of Yukon College and the First Nations administrations. A community presentation in the First Nation of $\mathrm{Na}$-Cho Nyäk Dun Government House in Mayo- including food prepared by Bobbie-Lee Melancon and ourselves - marked the official end of the LACE project. 


\section{Concluding Reflections}

This article lays out the process of conducting Community Based Participatory Research (CBPR) with the example of the research project "LACE - Labour Mobility and Community Participation in the Extractive Industries, Yukon." The key challenges in such projects include attracting a community partner that is interested in science in general, and ensuring that these projects are addressing the community's needs, which requires gaining knowledge about social processes going on within the local society. Trying to entwine local traditional (ecological) knowledge and Western science knowledge has the potential to overcome the hegemony of the latter and to push deeper insights into differing, but also joint, worldviews that can reconcile methodological conflicts.

For a First Nation, hosting a research project means that capacity has to be set aside to oversee the research process, to define the protocols for themselves and what should be the joint outcome. Not every community necessarily has the time and the personnel to deal with outsiders who are planning to stay for an extended period of time and who want to engage with a variety of social groups (e.g., Elders, youth, and other individuals), which have their own concerns and expectations.

A key question is why a First Nation should contribute to a research project producing knowledge that is also relevant beyond their community. We would like to acknowledge the First Nation of Na-Cho Nyäk Dun for allowing the LACE team to work on its traditional territory in order to contribute to the broader cultural heritage and knowledge on this planet. The Na-Cho Nyäk Dun people have a long history of interaction with the mining industry and therefore their case is particularly suited to studying societal impacts. Other regions in the Arctic and across the world can learn from these experiences. This is for sure not the first priority of the First Nation of Na-Cho Nyäk Dun. Nonetheless the whole community, including their self-government and the staff, contributed to this goal.

No doubt, one interest for the research team has been gaining general knowledge on the overall topic for the purpose of contributing basic research to the scientific community in the Arctic and, for Susanna Gartler, the PhD student on the project, a goal included the realization of her thesis. At the same time, in a CBRP project, this traditional scientific endeavour must be paired with considering why a community takes part and what the benefits are for them. In our case, a non-public report of the research findings relevant to the First Nation of Na-Cho Nyäk Dun and original interviews (only those where interlocutors' 
consent is given) will be provided to the First Nation of Na-Cho Nyäk Dun Heritage Department, and thus local access and ownership of knowledge will be secured. Furthermore, the jointly produced Mobile Workers Guide informs young men and women from the community about work life in the mining sector. The film "Mining on First Nation Land" targets not only locals but should give relevant information to mining companies that are already active or planning to explore and develop on the territory of the First Nation of Na-Cho Nyäk Dun.

It is essential to jointly develop goals and content of the research project in order to do away with the top-down and colonial research approaches of the past. This takes time and evolves not only in the initial stages but over the course of a project's lifespan. Benefits for the community in particular rest on the considerations that research can also benefit the community in understanding social processes in their community and to collect knowledge about cultural heritage; in this case it was the history and presence of the mining industry in their community. A principle of CBPR is to support policies and social changes in a community. LACE continues to develop materials that may give the community members, decision makers, and the general public insight into critical topics regarding mining on the traditional territories of Indigenous peoples, and regarding mining employment under conditions of rotational shift work. All these topics directly or indirectly address social changes and try to make developments visible in order for the community to be able to react to them.

At the same time, visiting researchers also benefit from such collaborative research. As a matter of fact, scholars would not be able to advance their careers without publishing or completing dissertations that rest on the willingness of a community to share knowledge and offer support. Furthermore, our team could expand the understanding of local concerns regarding research and research partnerships. We must acknowledge that a small community like the First Nation of Na-Cho Nyäk Dun and others we came across have really much more pressing issues to tackle instead of taking care of researchers in their community. The priority depends on the topic or if the researchers are invited by the community to tackle a specific question of interest. Another important aspect is to understand the complexity of confidentiality. Communities are small and stories collected might be recognized by others although they are anonymized. Scaling up the results is therefore important, as is generalizing themes that are identified. This may entail dropping whole topics in publications, even if they might be of interest to the public 
and the scientific community, where the protection of internal issues in communities and avoiding stigmatization has a higher priority.

Developing research partnerships and joint interests takes time and goes on over many years. Sometimes research funding does not allow for long-term research. But trustful partnerships have the potential to remain over long periods, beyond the original project, and to yield particularly rewarding results both for the scientists as well as for the communities. More creative funding mechanisms must be established that allow for temporal flexibility and to give seed money for establishing a partnership project before the actual research work starts. In successful cases of CBPR new projects and funding options are jointly developed. Time is the essential asset for good CBPR, especially when researchers are not yet familiar with the people they work with and vice versa.

\section{Acknowledgements}

I would like to thank the First Nation of Na-Cho Nyäk Dun, Chief Simon Mervin, the Council members, Joella Hogan (the manager of the Heritage Department), all the First Nation of Na-Cho Nyäk Dun citizens, and the Village of Mayo administration for hosting the LACE project so kindly. Big thanks go to Liz Blair, Beverly "Buffy" Genier, Josephine Hager, and Bobbie-Lee Melancon for their fruitful contributions and friendship. This collaboration has allowed me and the team members to gain new knowledge that supports our understanding of Indigenous world views and local concerns regarding the mining industry, its negative impacts, benefits, and debates surrounding it. I would like to thank all the people and interlocutors from Mayo and Keno City, and those I met in other places along the way in the Yukon, who shared their stories and knowledge. I thank PhD student Susanna Gartler for critical joint reflections and her endless support, as well as ReSDA research coordinator Valoree Walker and co-principal investigator Chris Southcott for the splendid teamwork. A special thanks goes to Peter Schweitzer, head of the Department for Social and Cultural Anthropology in Vienna, for his support of the LACE team. The research project "LACE-Labour Mobility and Community Participation in the Extractive Industries-Yukon" was funded by SSHRC (Social Sciences and Humanities Research Council of Canada) through the major collaborative research initiative ReSDA (Resources and Sustainable Development in the Arctic), the Yukon Government Department for Economic Development, and the University of Vienna. The project is affiliated with Yukon College, Lakehead University, the University of Vienna, and the Austrian Polar Research Institute. I thank the anonymous reviewers for their thought-provoking comments. In addition, I would like to acknowledge the fruitful comments by the AICBR-Arctic Institute 
for Community-Based Research in Whitehorse: thank you Norma Kassi, Jody Butler, and Katelyn Friendship for your review and friendship.

\section{Authors}

Gertrude Saxinger is assistant professor at the Department of Social and Cultural Anthropology, University of Vienna; faculty member of the Austrian Polar Research Institute (APRI); and adjunct researcher with the Yukon Research Centre at Yukon College.

First Nation of Na-Cho Nyäk Dun (Big River People) continue to live on their traditional territory in and near Mayo, Yukon, and represent the most northerly community of the Northern Tutchone language and culture group.

\section{References}

Abu-Lughod, L. 1991. "Writing Against Culture." In Recapturing. Anthropology: Working in the Present, edited by R.G. Fox, 137-162. Santa Fe: School of American Research Press.

Barth, F., Gingrich, A., Parkin, R., and S. Silverman. 2005. One Discipline, Four Ways: British, German, French, and American Anthropology. Chicago: The University of Chicago Press.

First Nations Centre (2007). OCAP: Ownership, Control, Access and Possession. Sanctioned by the First Nations Information Governance Committee, Assembly of First Nations. Ottawa: National Aboriginal Health Organization. Retrieved from http://fnigc.ca/sites/default/files/OCAP\%20First $\% 20$ Nations\%20Inherent\%20Right\%20to\%20Govern\%20First\%20Nations\%20 Data.pdf

First Nations Information Governance Centre. 2014. Ownership, Control, Access and Possession (OCAP ${ }^{\mathrm{TM}}$ ): The Path to First Nations Information Governance. May 2014. Ottawa: The First Nations Information Governance Centre, May 2014. http://fnigc.ca/sites/default/files/docs/ocap_path_to_fn_information_ governance_en_final.pdf

Gartler, S., Hogan, J., and G. Saxinger. Submitted. "Living Culture, Learning Skills, Telling our Stories: The Making of the Na-Cho Nyäk Dun Cultural Centre." The Heritage Journal. Submitted in November 2017.

Gehlert, S., Kye-Price, S., and V. Bekteshi. 2012. "Community-Based Participatory Research." Oxford Bibliographies, 1-11. https://doi.org/10.1093/ OBO/9780195389678-0157

Gong, F., Baron, Sh., Ayala, L., Stock, L., McDevitt, S., and C. Heaney. 2009. “The Role for Community-Based Participatory Research in Formulating Policy Initiatives: Promoting Safety and Health for In-Home Care Workers and their Consumers." American Journal of Public Health, 99(S3), S531-S538. https://doi. org/10.2105/AJPH.2008.152405. 
Graybill, J.K. 2015. “Teaching Energy Geographies via Videography." Journal of Geography in Higher Education, 1-12. https://doi.org/10.1080/03098265.2015.10 89474.

Holkup, P., Tripp-Reimer, T., Matt Saloil, E., and C. Weinert. 2004. “Communitybased Participatory Research: An Approach to Intervention Research with a Native American Community." ANS Advances in Nursing Science, 27(3), 162-175.

Jones, L., and K. Wells. 2007. "Strategies for Academic and Clinician Engagement in Community-Participatory Partnered Research." Journal of the American Medical Association, 297(4), 407-410.

Kassi, N., Pratt, M., Van Bibber, M., Friendship, K., Butler Walker, J., Alatini, M., Jonson, M.J., Alfred, R., Alfred, E., Kluane First Nation Lands, Resources \& Heritage Department, Kluane First Nation Youth and Elders, and the Vuntut Gwitchin Natural Resources Department. 2017. “The Partnerships, the Productions and the People Behind the Lens. Promoting Youth Wellness through Community-Based Research and Filmmaking." Northern Public Affairs, July, 26-32.

Krömer, A. (2016). Social Influence and Impact on the Collective Memory of the Native Residential Schools in Canada: 1867-1996. Doctoral thesis, University of Vienna, Austria. http://othes.univie.ac.at/44689/1/45108.pdf.

Malinowski, B. (2014[1922]). Argonauts of the Western Pacific. London: Routledge.

Minkler, M., and N. Wallerstein. (Eds.). 2008. Community-Based Participatory Research for Health: From Process to Outcomes. San Francisco: Jossey-Bass.

Norris, K., Brusuelas, C.R., Jones, L., Miranda, J., Duru, K., and C.M. Mangione. 2007. Partnering with Community Based Organizations: An Academic Institution's Evolving Perspective. Ethnicity \& Disease, 17, S1-27-S1-32.

Rahnema, M., and V. Bawtree. 1997. The Post-Development Reader. London: Zed Books.

Saxinger, G., and S. Gartler. 2015. Behind the Scenes in Yukon Mining: Work, Camp and Family Life in Yukon Mining Today. Stories collected in 2014/15. Full text with pictures from the presentation. Whitehorse: ReSDA. http://yukonresearch. yukoncollege.yk.ca/resda/wp-content/uploads/sites/2/2014/05/LACE-folder. pdf.

Saxinger, G., and S. Gartler. 2016. Behind the Scenes in Mayo and Mining: Na-Cho Nyäk Dun Elders' Opinions on Mining and Community History. Stories collected between June 2015 and March 2016. Full text of the presentation with pictures. Whitehorse: ReSDA. http://yukonresearch.yukoncollege.yk.ca/resda/wpcontent/uploads/sites/2/2014/05/LACE-folder2.pdf. 
Saxinger, G., and S. Gartler. 2017. The Mobile Workers Guide: Fly-in/Fly-out E Rotational Shift Work in Mining. Yukon Experiences. Whitehorse: ReSDA, First Nation of Na-Cho Nyäk Dun, Yukon College. https://fifo-guide.jimdo.com/; https://fifo-guide.jimdo.com/app/download/13733086030/

Saxinger, G., Gebauer, R., Oschmann, J., and S. Gartler. 2017. Mining on First Nation Land. The First Nation of Na-Cho Nyäk Dun in Mayo/Yukon Territory. First Nation of Na-Cho Nyäk Dun, YouTube video. https://www.youtube.com/ watch?v=u4UXywmkoqM.

Truth and Reconciliation Commission of Canada. 2015. Honouring the Truth, Reconciling for the Future: Summary of the Final Report of the Truth and Reconciliation Commission of Canada. Ottawa: Truth and Reconciliation Commission of Canada. http://publications.gc.ca/pub?id=9.800288\&sl=0. 